\section{Living around the world}

\author{
Barry Cox
}

Biogeography and Plate Tectonics. By J. C. Briggs. Elsevier:1987. Pp.204. Dfl. $155, \$ 75.50$.

BRIGGs's book has an exciting title. Study of the interplay between the dispersal of organisms, and the dispersal or collision of continental fragments resulting from plate tectonics, has already solved some longstanding problems and thrown new light on others.

In the past few years, biogeography has also been the forum for an often acrimonious debate between rival groups. First, there are those who believe that dispersal across pre-existing barriers is the important theoretical model for the analysis of historical biogeography. Secondly, there are those who instead support the idea of vicariance biogeography, in which the barrier is believed to have arisen later, dividing a formerly continuous population into two groups with new and independent destinies. Because adherents to the two camps often seem to view their own theory as the only possible one, it is encouraging to read Briggs's statement that his ". . . book has been written from the point of view that dispersal and vicarianism have each played an important role in historical biogeography" - a promise of a balanced approach.

The book is composed of three main parts. The first, "The Northern Continents", is divided into sections that deal with each of the intercontinental connections - the North Atlantic, North Pacific (Beringia), Caribbean and Indo-Australian. In Part 2, on the Southern Continents, Briggs takes a different approach, dealing with each land mass in turn (including New Zealand, Madagascar and India). These differing approaches are sensible, for they reflect the greater complexity of the biogeography of the Southern Hemisphere, resulting from the greater fragmentation of old Gondwanaland.

Within each section, Briggs outlines the apparent historical biogeography of each main group in turn (for example freshwater fish, reptiles, mammals, flowering plants, insects), and discusses or summarizes the plate tectonic data. Although each section does also contain a final summary, it might have been preferable if more integration had been attempted by tracing each land-mass through time and noting the extent to which dispersals demanded by the biotic data are compatible with one another and with the plate tectonic data.

By background Briggs is a specialist on marine zoogeography, and we are reminded of this by the presence of an

unusual third part, on the oceanic plates. Here there are some useful comments on the patterns of speciation and endemism on islands, and on the contrasts between the endemism of terrestrial and marine organisms associated with oceanic islands. The book ends with a bibliography of about 500 entries, and a series of nine world maps from the Triassic to the present day that show the distribution of land and sea. Each map shows only the contemporary coastlines, and is rather roughly and schematically drawn. In general, the book is rather poorly illustrated, for there are only 18 other figures.

At times, I wondered whether Briggs had read widely or deeply enough. Do most palaeobotanists still accept Takhtajan's theory that the flowering plants originated in South-East Asia, rather than the palynological evidence that suggests an origin in the tropics of Africa-South America? Similarly, is the concept of an Arcto-Tertiary Northern Hemisphere

\section{Progress in gaps}

Daniel Goodenough

Cell-to-Cell Communication. Edited by Walmor C. De Mello. Plenum:1987. Pp.374. $\$ 59.50$ (North America), $\$ 71.40$ (elsewhere).

THE 'gap junction' community has evolved to a steady state of having an international meeting once every two years. The availability of a summary of these meetings in book form has been variable, depending on the needs of the meeting sponsors. Nonetheless, we do have one excellent volume containing a review of research on gap-junctionmediated intercellular communication (a 1985 Cold Spring Harbor book, edited by M.V.L. Bennett and D.C. Spray). A forthcoming volume, edited by E.L. Hertzberg and R. Johnson, will include papers presented at a meeting at Asilomar in July 1987, and will be published in July this year by Alan R. Liss.

Cell-to-Cell Communication thus falls temporally between two important books about gap junctions. The title is somewhat pretentious because the volume is almost entirely about gap-junctional intercellular communication. The editor recognizes this, and himself includes a contribution intended to summarize all other forms of intercellular communication - an impossible task for one chapter.

The volume is loosely organized, containing a collection of individual chapters which vary in scope and purpose: they range from those presenting large amounts of the authors' own data (Peracchia, Berdan), to theoretical musings (Sheridan), to concise, critical reviews (Guthrie), flora still accepted? Is it so certain that New World monkeys and rodents reached South America from the north and not from Africa? Briggs gives us statements, rather than discussions, on such points, so that one can never be sure of the degree of certainty that lies behind each.

Excluding the historical introduction, maps, bibliography and other ancillary material, however, the book is effectively only 135 printed pages long. This is perhaps not enough space to give an authoritative explanation of a subject that requires judgements on the histories and phylogenies of many animal and plant groups. Nevertheless, Biogeography and Plate Tectonics is clearly written and well laid out, with an up-to-date and wide bibliography, and will serve as a useful starting point for those who wish to take the subject further.

Barry Cox is a Professor in the Department of Biology, King's College London (KQC), Campden Hill Road, London W8 7AH, UK.

to those that teach the basic concepts (Jaslove and Brink). The book suffers from two unavoidable drawbacks inherent to its species. First, almost all the authors cover only published information, saving their unpublished material for reviewed journals. An exception is the chapter by Berdan, who presents a great deal of eagerly awaited data on progress with the isolation of arthropod gap junctions. The second defect of review volumes that the contents tend not to be up to date, because of the difficulty of trying to coordinate so many authors - is particularly noticeable here. Research on gap junctions has entered the area of modern molecular biology in the past two years, and this book misses the excitement.

Individually, the chapters present indepth summaries of published work, and so are useful in that respect. In particular, Guthrie provides a helpful, critical assessment of the literature. But, for example, although Zampighi and Peracchia include all the relevant papers, unlike Guthrie they do not attempt to give any insight as to why different results are found in different laboratories.

Cell-to-Cell Communication thus falls not only between the two meeting reports on gap junctions mentioned at the beginning, but also falls between being an upto-the-moment summary of data and a tightly edited volume designed for teaching use. All researchers interested in gapjunctional communication will find material of interest here, but most of it has simply been reworked and lacks the excitement of the recent advances in molecular biology.

Daniel Goodenough is a Professor in the Department of Anatomy and Cellular Biology, Harvard Medical School, 220 Longwood Avenue, Boston, Massachusetts 02115, USA. 